\title{
CHARACTERIZATION AND PROPOSALS FOR RECOVERY OF TRADITIONAL TAMANG CONSTRUCTION IN NORTHERN NEPAL
}

\author{
F. J. Castilla ${ }^{1, *}$, J. Agulló ${ }^{2}$, J. Castellote ${ }^{3}$ \\ ${ }^{1}$ Universidad de Castilla-La Mancha (UCLM) Escuela Politécnica. Cuenca 16071. Spain - fcojavier.castilla@uclm.es \\ ${ }^{2}$ Universidad Europea (UE) Escuela de Arquitectura, Ingeniería y Diseño C/ Tajo, s/n. \\ Urb. El Bosque 28670 Villaviciosa de Odón (Madrid). Spain - jose.agullo@universidadeuropea.es \\ ${ }^{3}$ Castellote + Arquitectos. C/Enrique Larreta 3, Bajo A, 28036 Madrid, Spain - jcdelolmo@ castellotearch.com
}

Commission II - WG II/8

KEY WORDS: Nepal, Tamang, Seismic Risk, Stone construction, Timber structures

\begin{abstract}
:
This article is the result of the work of four years of field trips (2016-2019) to the village of Gatlang (Nepal) and visits to some of the surrounding villages in the Rasuwa district. This area is mainly inhabited by Tamang, of Buddhist culture and of distant Mongolian origin. The architecture of the Tamang ethnic group is unique although shares some common characteristics with other mountain or isolated architectures around the world. Due to its difficult access and remote location of these communities, the architecture uses mostly local materials (stone and wood). Although this characteristic is common to many other communities of the Himalayan mountain range, even today it is possible to differentiate architectural styles associated with ethnic groups in different regions. The primitive state of these constructions is progressively altered by the inclusion of new materials, especially in areas affected by earthquakes, such as this one, where the urgency and need to guarantee the safety of new constructions has resulted in disparate and uncontrolled reconstructions. The article aims to identify and analyze Tamang vernacular architecture constructions, their invariants, and gain in-depth knowledge of their general behavior when faced with environmental factors, as well as conservation possibilities. The final objective is to promote the recovery of this architecture, guaranteeing its structural safety and adapting it to the current habitability needs, but trying to maintain the typological invariants that preserve its value as a set of historical, cultural and tourist interests, which form part of the Tamang Heritage Trail.
\end{abstract}

\section{INTRODUCTION}

\subsection{Project context}

In this paper, we describe and make an analysis of the construction and invariants of the houses and architectural elements associated with the Tamang culture, their general behavior to face environmental factors and an approach to their seismic behavior, since many of them were destroyed partially or totally during the earthquake of May 2015. It is the result of four years of field trips (2016-2019) to the town of Gatlang (Nepal) and some of the surrounding villages in the Rasuwa district, situated about $150 \mathrm{~km}$ North of the capital Kathmandu and thanks to the NGO-Orche.

The population of Nepal is divided by ethnic groups spread out over different districts, Rasuwa hosts mostly the Tamang, of Buddhist culture and far Mongolian origin, as other ethnic groups of the mountains such as the Gurung (Annapurna area) or the Sherpas (Everest area). The architecture of the Tamang ethnic group is very unique and is quite similar to the architecture of the Sierra Negra de Guadalajara (Spain). Due to the difficulty of access and degree of isolation of these communities, the architecture uses mostly local materials (stone and wood) as it happened for many years in the farthest places of the mountains of the Iberian Peninsula. This characteristic is common to many other communities of the Himalayan mountain range, which allows us to differentiate architectural styles associated with ethnic groups in different regions (Oliver, 2000).
The primitive appearance of these constructions is being progressively altered by the inclusion of new materials, especially in areas affected by earthquakes, such as the Himalayan ridge, where the urgency and need to guarantee the safety of new constructions has led to disparate and uncontrolled reconstructions. Moreover, other architectural elements associated with the traditional way of life are also threatened and led to their disappearance due to changes in customs.

\subsection{Location: geographic and climatic characteristics}

Gatlang is located in a mountainous geographical area (between the Kathmandu valley and the high ridges of the Himalayas) at an average height of 2,200m above sea level and according to the Köppen climate classification it belongs to the Dry-inter subtropical highland climate zone $(\mathrm{Cwb})$. The terrain is very hilly with very steep valleys, so the population usually scatter in those more open areas of the rivers or on the sunny slopes or upper parts of the hills. The year is divided into a wet season from June to September, and a dry season from October to June. During the first one, the summer heat in Inland Asia creates a low-pressure zone that attracts the moist air of the Indian Ocean, characterized by the presence of the Monsoon. During the second one, cold temperatures in the vast interior create a high-pressure zone that causes dry air to flow out. Temperatures can reach extreme variations, near to $30^{\circ} \mathrm{C}$, between day and night by this time. Precipitation generally decreases from east to west of the country and the area of Kathmandu receives about $1,400 \mathrm{~mm}$ annually.

\footnotetext{
* Corresponding author
} 
Adiabatic effects modify this pattern: the ascending air masses cool down and their moisture content decreases on the windward slopes, then they warm up as they descend and the relative humidity decreases.

The rains decrease in September and generally end in midOctober, marking the beginning of the generally cool, clear and dry climate, as well as the more relaxed and jovial period in Nepal. By this time, the harvest ends, and the festive atmosphere characterizes the local life. The two largest and most important Hindu festivals, Dashain and Tihar (Dipawali), arrive during this period, one month apart. Risks such as earthquakes, severe thunderstorms, floods, landslides are common in this area, as analyzed in the Global Assessment of Risk (2009), which affect buildings, ruin crops, and in addition complicate the transport as unpaved roads may become unusable.

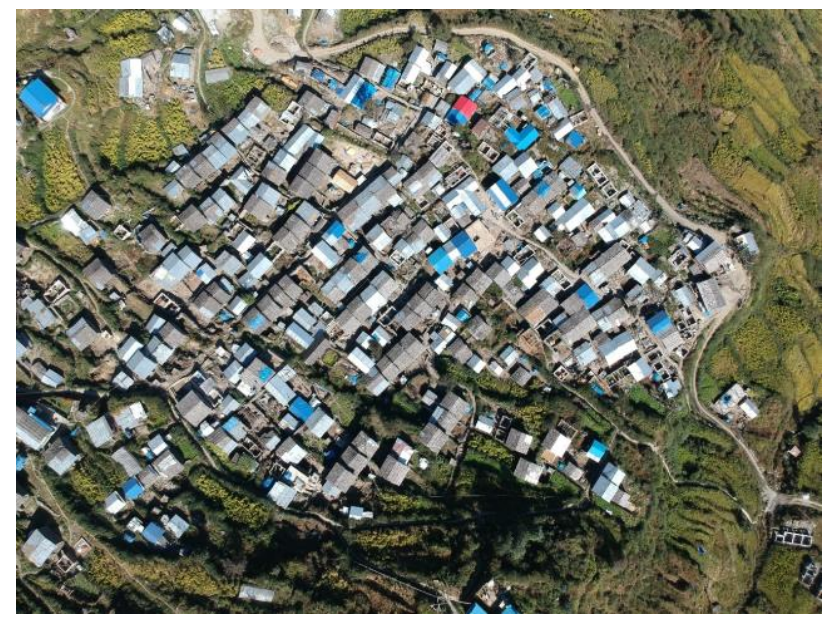

Figure 1. Aerial view of Gatlang

(Álvaro Rodríguez. UEM student).

\subsection{Characteristic architectonic elements and evolution}

In the 13th century, a group of people from Tibet decided to build a new village near Lake Aamachhodingmo, considered by them to be a sacred lake. Later in the 14th century another village was founded to the northeast and at a lower altitude, this village is the one that we can consider as the current Gatlang.

Nowadays, Gatlang has a population of around 1500 people in 300 houses, some of them built hundreds of years ago. When analyzing its architecture typology, construction materials and decoration of the houses it can be deduced that, the first ones were built in the lowest part of the village, closer to the river. In this area, some houses that have carved finishes, in stone and wood, can be found, which are not found in the houses of the highest part. Unfortunately, this area was the most affected by the earthquake and houses with these characteristics are just a few.

As remarkable elements, Gatlang is surrounded by 108 chortens to protect the people from natural misfortunes and evil spirits. These chorten are very different from the ones found in the surrounding areas. In addition, there are nine water mills along the small river that runs through the village. They use the force of the water to move a small wooden propeller that turns a grinding stone. The mills are used to grind the grain coming from the nearby harvest: mainly corn and lentils. Mills are buildings that belong to a family who is in charge of the grinding for which they earn some money. All these elements are detailed in section 2 .

\subsection{Urbanization and bioclimatic behavior}

In the town of Gatlang the urbanization presents a very clear order (although with an irregular and winding layout) in rows of terraced and staggered houses in the direction of the maximum slope of the hill, descending in the northeast direction (Figure 1).

The houses are usually built on horizontal terraces where groups of three to five detached houses are located. The slope does not favor facades facing south, so the main openings in the houses face to the southeast, with ample space between one row and another, permitting solar gains (Figures 2 and 3).

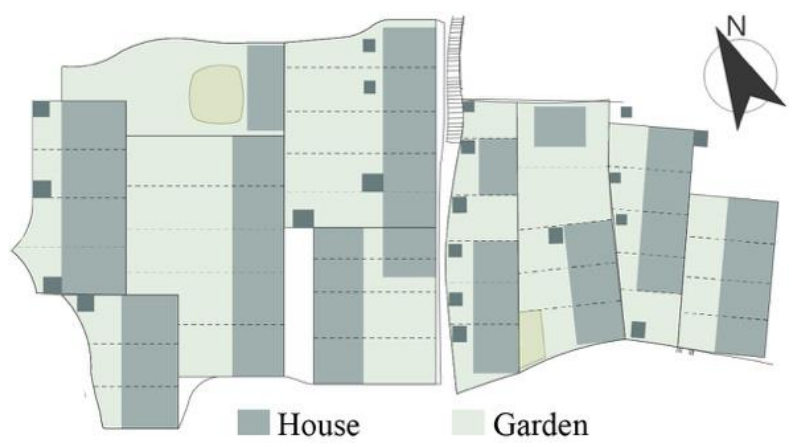

Figure 2. Detailed distribution of houses and open-air areas. Plan view (Authors).

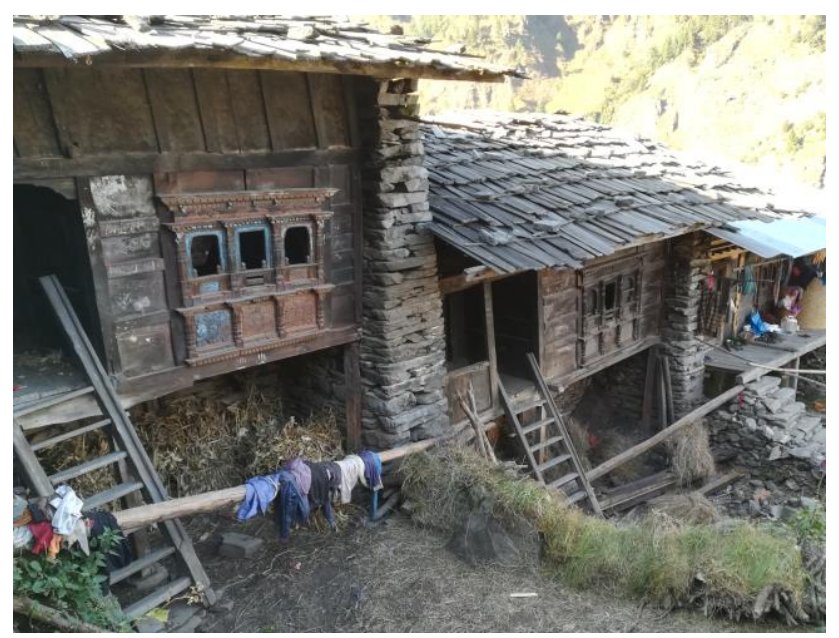

Figure 3. Group of staggered housing (Authors).

This space between the rows of houses is used as a communal passage area or an orchard area. After the earthquake in 2015, they were filled, in many cases, by temporary makeshift dwelling made of wood, metal-sheet and canvas. The consequences of the earthquake affected almost the entire village and a large part of the houses collapsed or are damaged, forcing its inhabitants to live in precarious conditions.

Many of the passageways are still blocked by debris and the village is in process of general reconstruction. Over the last three years, provisional housing has been converted into definitive brick and concrete housing thanks to the help of the government and international organizations however, they have not promoted the conservation of the typical typologies of traditional architecture (Figure 4). 


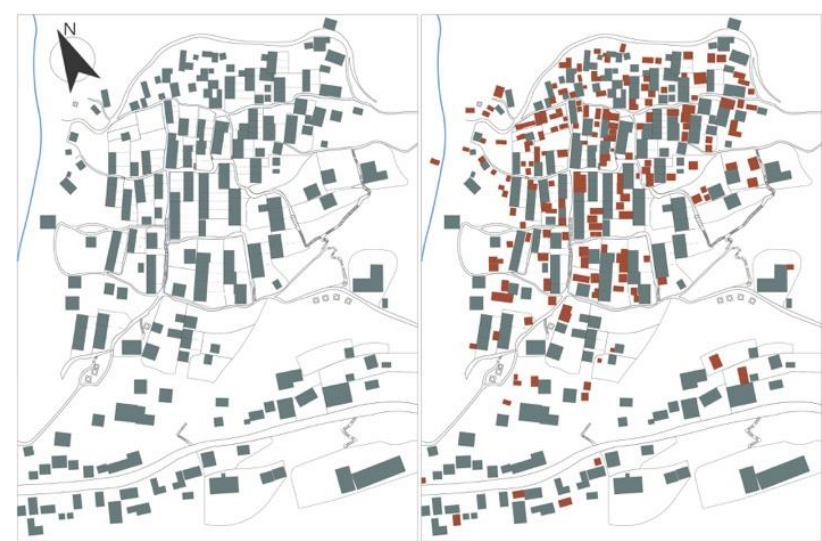

Figure 4. Left map - Gatlang traditional houses - Right Map. 2016- Gatlang traditional houses and makeshift dwelling marked in red. 2019 (Authors).

The configuration of the traditional dwellings takes advantage of the great thermal inertia envelope on three sides of the perimeter, with the exception of the main façade, which is made of light-wood and is more permeable to sun and air. The sloping roofs with large eaves prevent the accumulation of water by direct runoff towards the intermediate spaces between the rows of houses.

\section{TYPES OF TRADITIONAL CONSTRUCTIONS}

\subsection{Dwellings}

Traditional housing in Gatlang does not differ too much from those found in other nearby towns, such as Chilime, Tatopani or Thulo Syabru. The traditional settlement however is less affected, as fewer new constructions can be found in the center of Gatlang. The most common typology, and possibly the oldest, is a two-story squared building measuring $6 \times 6 \mathrm{~m}$. This type of dwelling is repeated with greater profusion in the village and to which we refer in this article. There are other less frequent housing typologies such as L floor shape or singlestory rectangular buildings. Larger housing as described in Emergency Architects (2016) can also be found

Many modern typologies, with very different constructive and structural configurations, are being added to the older ones at very high ratio since the 2015 earthquake. (Agulló, 2019)

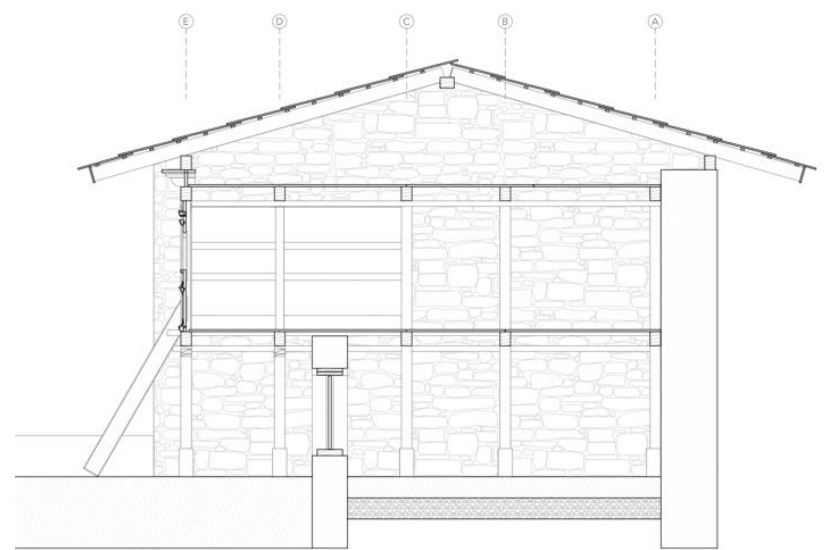

Figure 5. House section (Authors).
2.1.1 Architectural description and uses: The referred typology of dwellings is characterized by its heavy $60 \mathrm{~cm}$ thick stonewalls (two of them sheared with the neighbors), and its handcrafted facade carved in wood. The roof, structure and interior partitions are also made of wooden poles, beams and planks. The house is distributed as follows. A ground floor for storage or stables, generally without compartmentalization. A main floor accessed by an outside veranda or balcony (covered by a large eave) which in many cases serves as a drying area, weaving room or hosting other domestic cares. An additional space under the roof (loft), varying in heights generally used for storage of grain or other household possessions (Figure 5).

The stonewall of the main facade in the ground floor is set back from to the upper floor, which allows a covered outdoor space and access. At present, most of the houses preserve a main room (with average dimensions of $3.20 \times 5.70 \mathrm{~m}$ ) that occupies slightly less than two thirds of the floor, where the fireplace / kitchen is located (and serves as a living roombedroom). The furniture and storage spaces are located in the perimeter. The remaining part is usually occupied by a small open-air access hall, an intermediate storage space and a small room that serves as additional bedroom $(2,00 \times 3,00 \mathrm{~m})$ Access to the space under the roof, when this is usable, is done by a ladder. The disposition of these spaces generates different facade compositions, depending on the size of the entrance, the balcony or the height of the loft. The evolution of these compositions has been studied in Agulló, 2019. Although the differentiating element of most homes is the central wooden panel window, which (together with small openings in the opposite facade) allows lighting and ventilation of the interior space and is explained in detail in section 2.1.3.

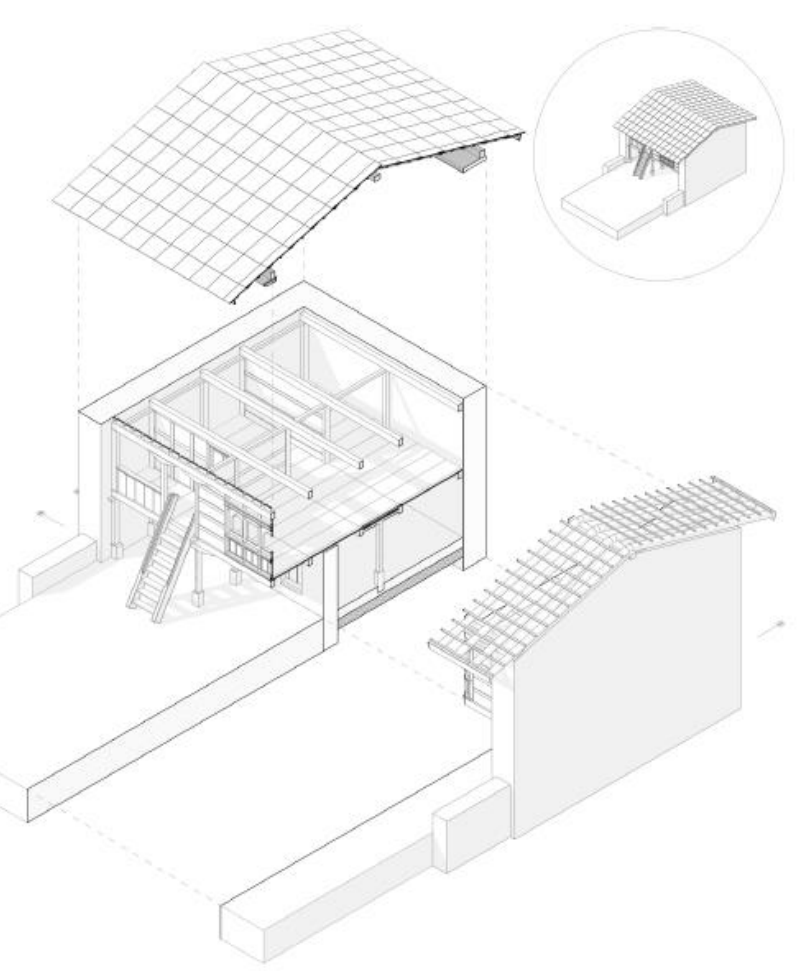

Figure 6. Interior distribution axonometric view (Authors). 
The loft is ventilated by means of the gaps in the roof covering, which is not air tight, and illuminated by small perforations with different geometric patterns on the panels of the main facade. The height of the ground and main stories varies from $1.90 \mathrm{~m}$ to $2.00 \mathrm{~m}$ and $0.80 \mathrm{~m}$ to $1.50 \mathrm{~m}$ in the loft, from the timber floor to the ridge. (Figure 6)

2.1.2 Description of the construction and structural system: The heavy stone envelope houses a lighter wooden structure inside, almost independent of the first. The stonewall has only one or two square openings in the west facade $(0.60 \mathrm{~m} \times 0.60 \mathrm{~m})$, with lintels made of the same stone and simple wooden shutter. It can be seen that with the incorporation of more modern woodwork (double shutters) and glass, some holes have been expanded to $0.90 \mathrm{~m}$.

The supporting structure of the floors is built up of wooden poles, with square section (between 10 and $12 \mathrm{~cm}$ side) and beams of a single piece of practically square section (between $10 \mathrm{~cm}$ and $15 \mathrm{~cm}$ side) configuring three frames (with four bays $1.50 \mathrm{~m}$ span) perpendicular to the main facade (one central and two attached to the perimeter walls). Over these, five wooden beams of similar section are placed, coinciding with the position of the underneath poles. They support the interior loads and help in the structural behavior in case of earthquakes. The timber floor is formed by wooden planks ( $8 \times 25 \mathrm{~cm}$ of medium dimensions) spanned from beam to beam. (Figure 7)

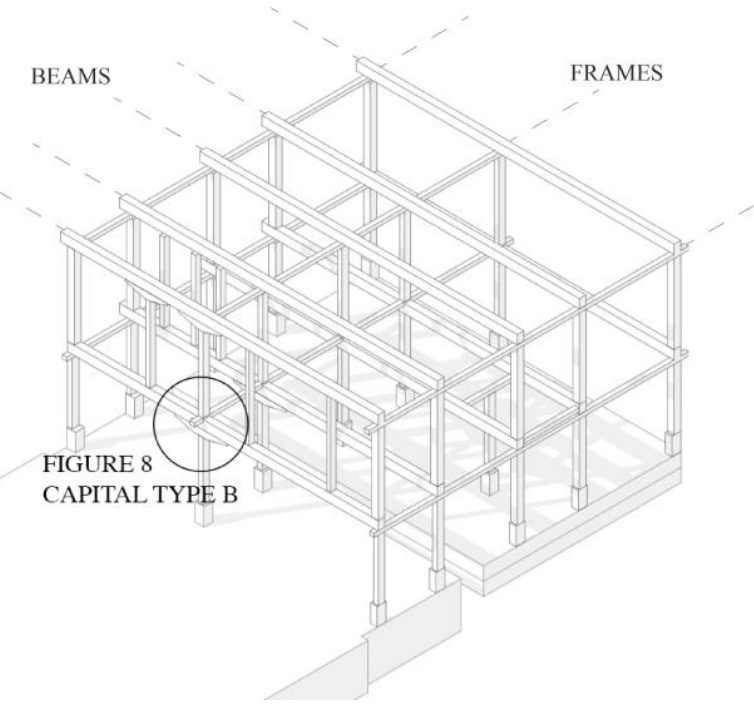

Figure 7. Timber structure axonometric view (Authors).

This structure is repeated both on the first floor and on the second floor, conditioning in some way the distribution of the interior space on the main floor. Usually, in this floor, only the extreme and central poles of each frame are conserved.

The roof is formed by large wooden tiles overlapped in horizontal rows that offset from the eave to the ridge (between 8 or 10 rows, depending on the length of the roof and the overlap). The fastening system is done by gravity, using bamboo cane slats, weighted with stones, which also forms one of the most characteristic images of the place, despite the profusion of canvas and sheet metal panels, because of emergency repairs after the earthquake of 2015.

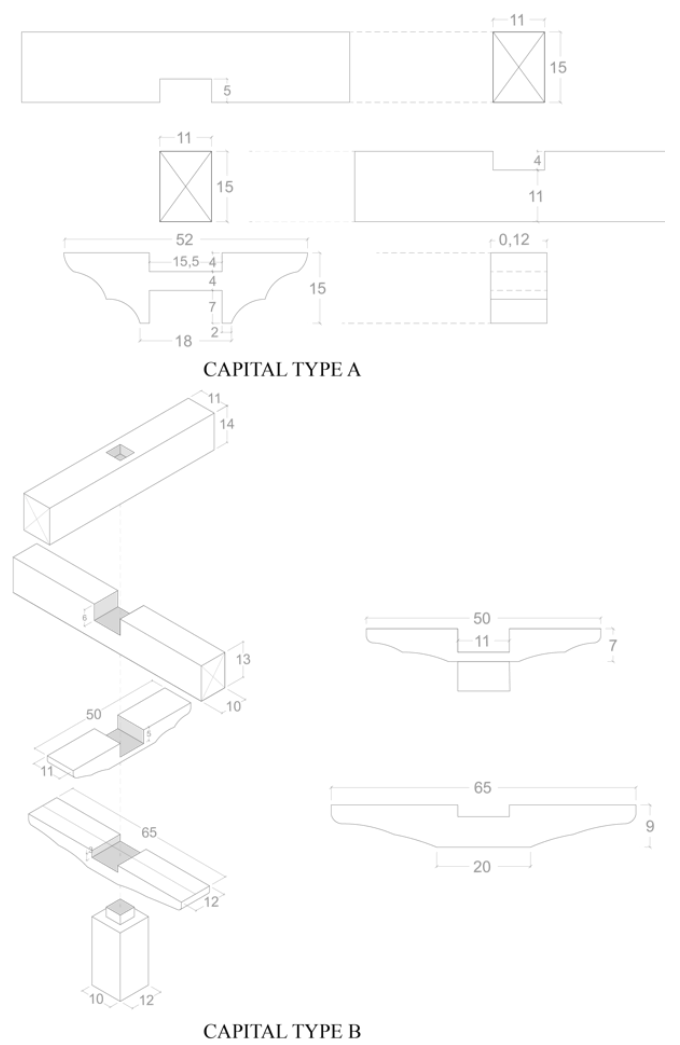

Figure 8. Detail of structural assemblies (Authors).

The assemblies between pillar and beams are usually made of mortise and tenon, while between beams they are half lap. It is not usual to use nails. In the main façade and in the central frame, the beams rest on ample capitals, both on the ground floor and on the main floor (Figure 8)

2.1.3 Special constructive elements (façade wooden panels): As a closing of this framework, on the main facade, a fine carpentry work is carried out, with assembled pieces, more typical of joinery than timber crafts. Panels between 40 and 50 $\mathrm{cm}$ wide form the facade, joined by slats of 10 to $12 \mathrm{~cm}$ wide, which are interrupted to place the main sculpted piece with the openings and shutters. All of the houses have these fronts with a strong symbolic character. The fronts are made up of one or three pieces and have wood engravings that makes them very unique within the architecture of the village (Figure 9).

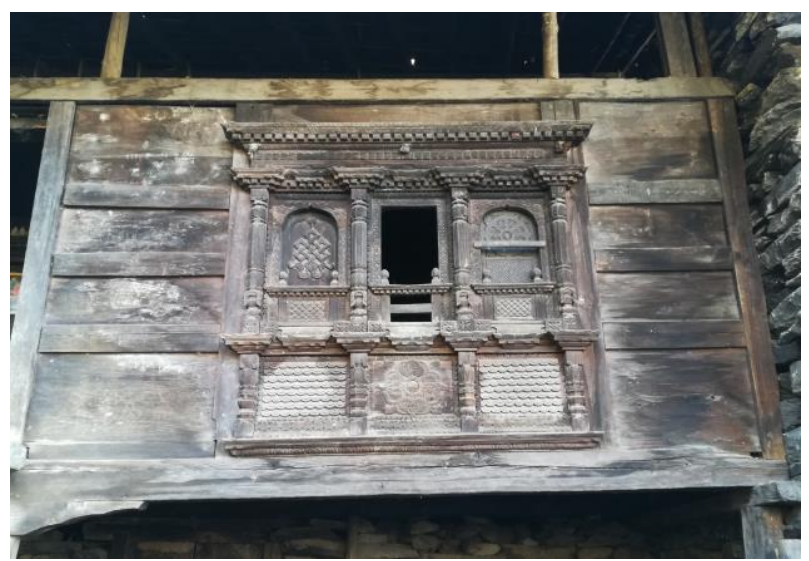

Figure 9. Wood facade (Authors). 
These engravings correspond to the eight auspicious signs of Buddhism (Ashta Mangala) that have their roots in the dharmic tradition. The Dharma has its origin in the Sanskrit, Indian language; it means "law" or "reality" and represents in Buddhism the teachings to eliminate suffering. It is represented by a wheel that symbolizes the cycle of life, death and reincarnation that never stops. These symbols are used in houses of Gatlang as auspices of good luck charms within Buddhist practices.

\subsection{Water Mills}

After the earthquake of 2015 , only two of the existing mills in the village were operational and the earthquake had damaged all. Two out of nine mills seemed to have been out of operation for long time due to the ruined aspect of the machinery.

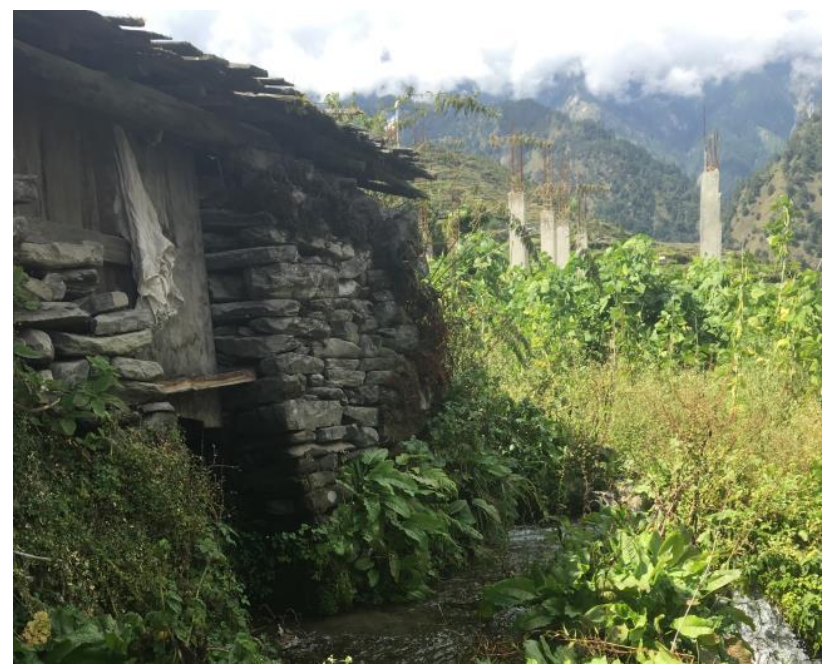

Figure 10. Downstream façade of a mill (Authors).

2.2.1 Milling operation: The grinding process is quite rudimentary, according to the technology available. The water is channeled from the river by a small pipe that enters into the lower part of the building. The jet water hits some vertical vanes inserted in a vertical wooden shaft, which rotates with the water pressure. The shaft is anchored at the bottom to a hole in the stone and at the top to a rotating stone (the upper stone of the mill). The lower stone rests on a wooden board that covers the lower part of the building. A box made of vertical wooden boards surrounds both stones and creates the area to collect the grinding. The grain is gradually thrown out of container hanging from the ceiling, which is filled from time to time by the miller (Figure 11)
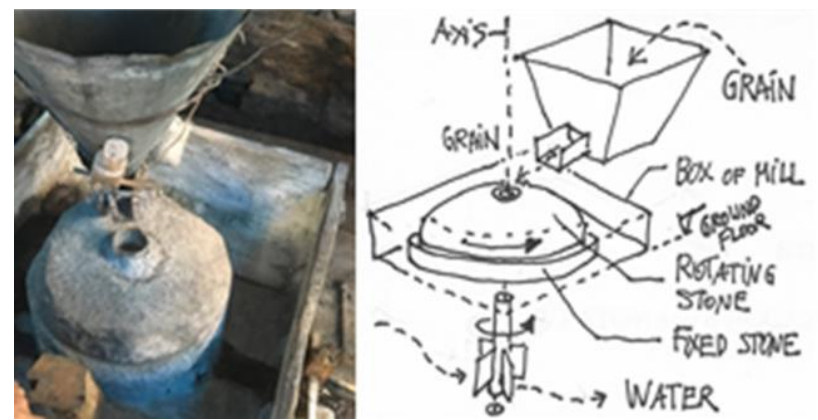

Figure 11. Mill machinery (Authors).
The grain enters the loose hole in the upper stone and is trapped between the slots of the two stones that grind it. The work rate is slow because the stones are small, and the amount of grain input is limited.

\subsubsection{Description of the construction and structural} system: The buildings of the mills follow the general scheme of the dwellings previously exposed but clearly, they have a simpler construction, less cared and it seems one of the causes of their fast deterioration (Figure 10)

The base is a rectangle (or "L" shape sometimes) of stone that starts at the water level, where the propeller is hosted, and rises up to the ground floor, where the grinding machinery is placed. This perimeter of the stonewalls has an open area where the water comes in. It is built with a wooden beam and a wooden board enclosure over it. On the ground level, a wooden floor is supported by the edge beam and an interior wall. The floor occupies only half of that surface, which is necessary to cover the passage of water and the propeller (Figure 12)

The gabled roof consists of a wooden beam, which has the span of the floor longest size, supporting bamboo joists, which form the slope. Other bamboo sticks are arranged in a disorganized way between the joists to support the timber tiles. In some mills, a column is placed reducing the span of the beam. There are no bracings in the plane of the ridge beam, which makes the roof structure very unstable lengthwise.
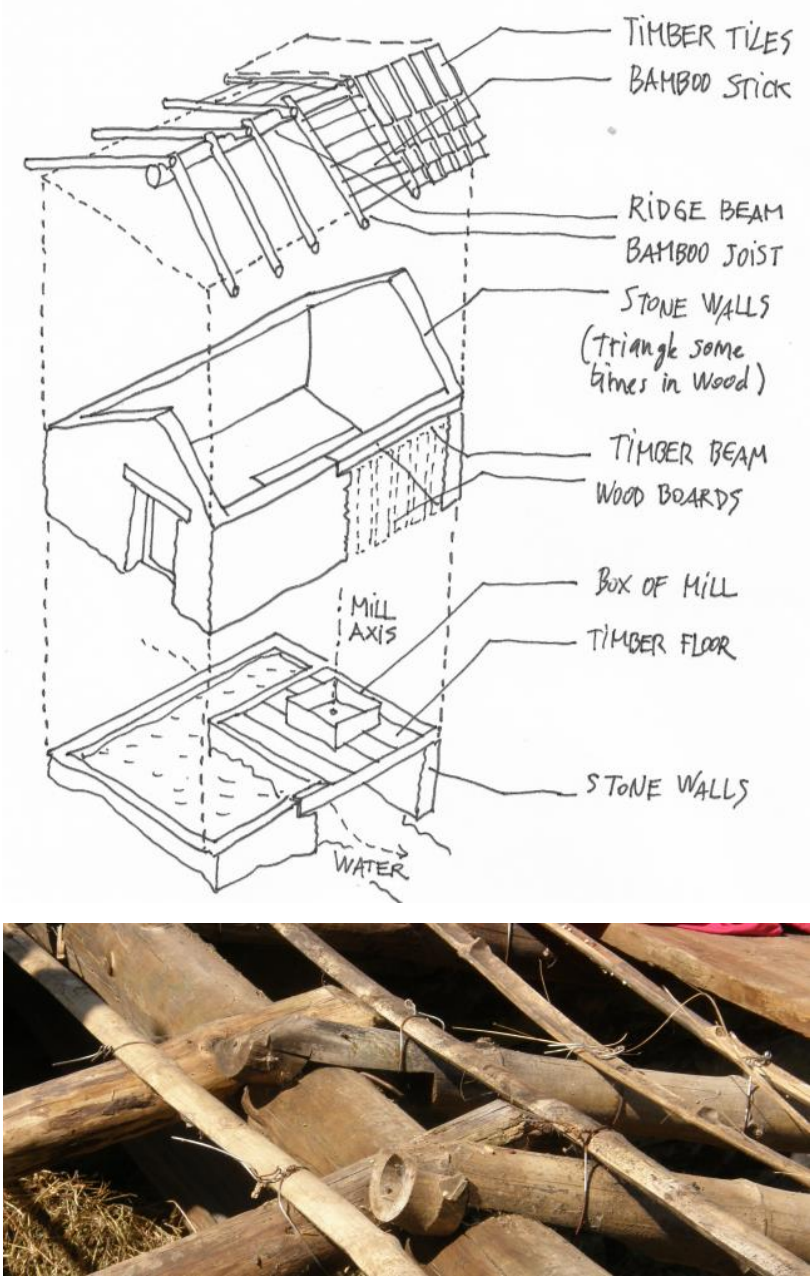

Figure 12. Constructive elements and ridge beam (Authors). 


\subsection{Chorten}

2.3.1 Description and use: The chortens are one of the most characteristic religious constructions in Buddhism; one of their translations of Tibetan is "receptacle of faith" as a sign of the spirit. Its origin is in the Stupas, ancient Indian tombs where Buddha was buried, so it is believed that the first of the chortens kept the remains of Buddha. Today they usually contain religious texts, relics or objects of a holy lama or someone of importance within the community. It is because of this Hindu origin, and its subsequent use in Buddhist culture, that the chorten can be found throughout Asia. This expansion across the continent leads to many variations in its construction from one region to another, but all of them maintain a number of concepts regarding their geometric composition (Figures 13 and 14) and symbolism as a representation of the path to "awakening". Its construction or subsequent restoration is considered of great value to those who do it. As in other religions chortens should be surrounded clockwise, the circumambulation of a chorten is called Kora (Tibetan) in reference to the peregrinations to sacred places in Tibet. According to Buddhism, performing this exercise helps in meditation and achieve the desired wishes

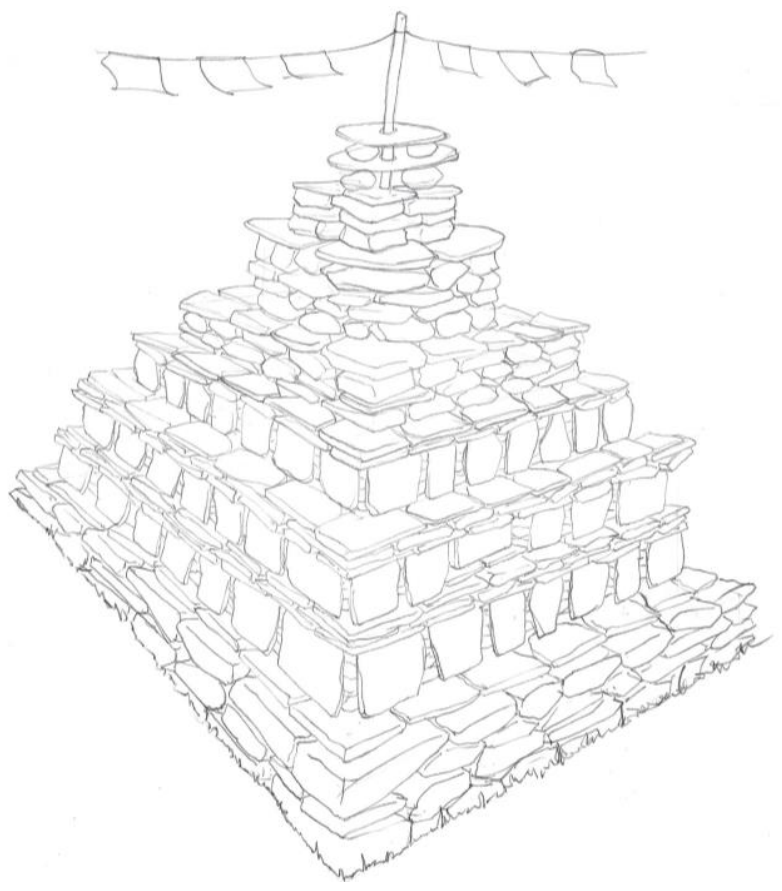

Figure 13. Axonometric drawing of stone chorten (Authors).

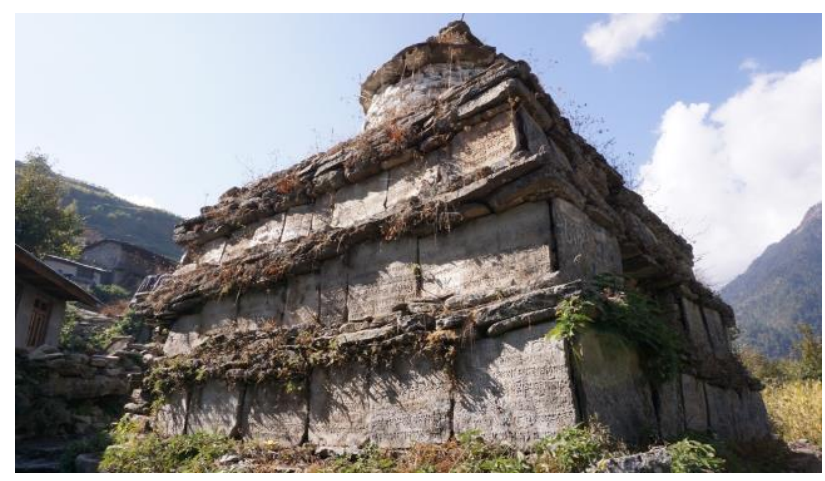

Figure 14. Chorten in Gatlang (Authors).
2.3.2 Characteristic elements: In Gatlang it is very common to find chortens, when making trips to other places, such as temples or neighboring villages, and within the village, chortens are considered of great value within the community and have many unique characteristics compared to chortens found in other areas. Most of chortens consist of five parts that symbolize aspects of Buddhism and Hinduism such as the five elements of the universe (Figure 15) or the Buddhas of meditation Gatlang chortens have fewer parts due to their simpler construction.

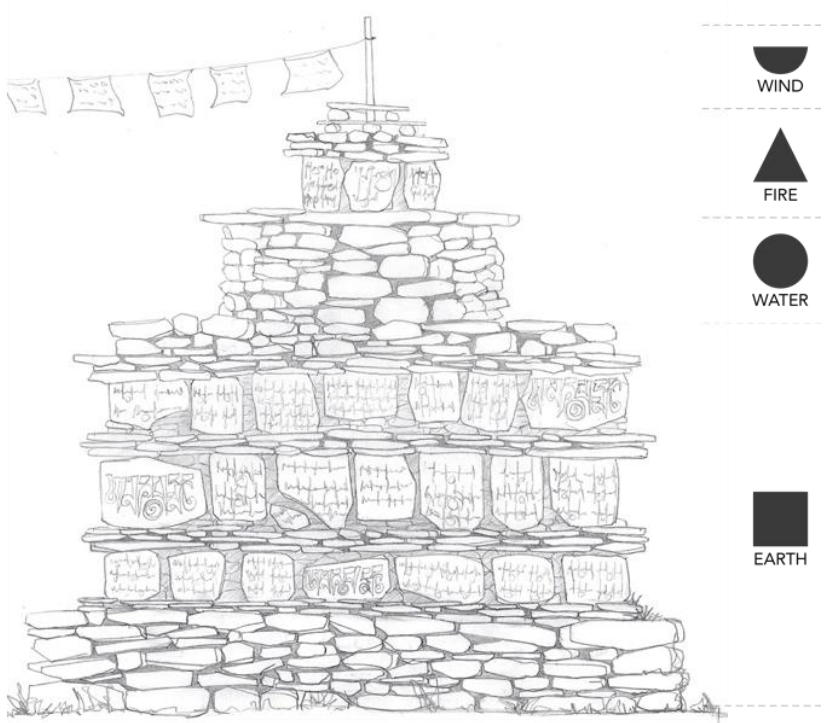

Figure 15. Front view of stone chorten (Authors).

2.3.3 Description of the construction: Unlike other chortens, the ones found in Gatlang are made entirely of undecorated stone. The interior structure is built using layers of rubble over a layer of large stone ashlars. To give the geometric shape to each part of the chorten, stone slabs are placed vertically in the perimeter. These stones are called Mani stones. Mani stones are one of the most common forms of prayer in Buddhism. They are shales slabs or phyllite slabs engraved with mantra "Om mani padme hum" (Figure 16).

This mantra has six syllables with different qualities. Each one helps to avoid reincarnations within the six kingdoms, purify the body, speech and mind and also represents the six main virtues that are generosity, patience, concentration, wisdom, education and ethics. This mantra is considered one of the main mantras of Buddhism, since it combines all the teachings of Buddha.

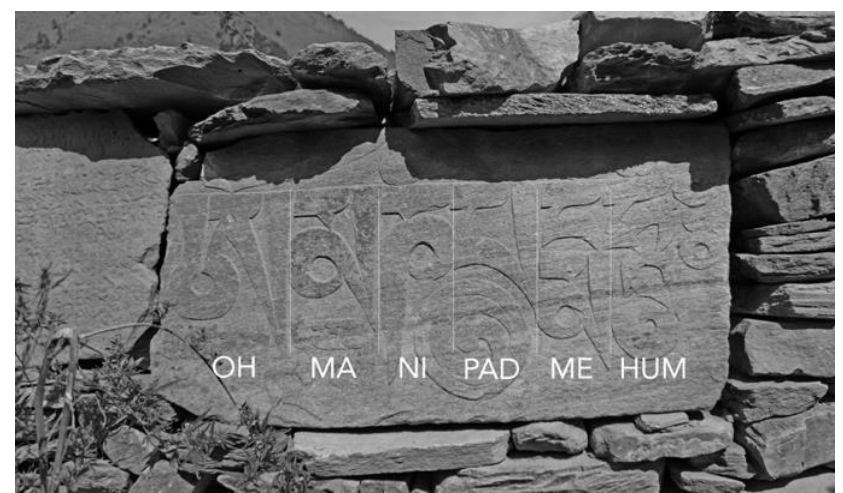

Figure 16. Detail of Mani Stone (Authors). 


\section{PROBLEMS AND CRITERIA FOR RESTORATION}

\subsection{Structural Safety}

3.1.1 Observation of damage on buildings after the earthquake: The structures of the Tamang buildings are clearly differentiated between the stone perimeter walls and the wooden framework. The walls formed by stones without mortar have the great problem of crumbling by throwing the stones from the parts with less vertical load such as the gables. Besides the lack of mortar, the irregularity of the stones makes the supports between stones very unstable even before an earthquake and therefore very sensitive to horizontal actions. The wooden structure in most cases has remained standing although deformation greatly due to the lack of vertical bracings. The stone structure has no ductility and suffers from very brittle breakage. The wooden structure however has great ductility, which allows it to resist with great deformations.

The interaction between both structures during earthquakes can also produce collapse. It is commonly observed that detached stones have sunk wooden roof structures of the buildings down the slope in their fall. It is also observed less frequently that the oscillatory movements of the wooden structures have hit the stone walls causing their collapse (Figure 17).

As described in Singh (2016), the common causes of collapse in buildings in Nepal are due to the lack of tensile elements in masonry, which could minimize the above problems. There are no horizontal or vertical ties in the masonry made of traditional materials such as wood or bamboo.

Other studies (Gautam, 2015; Sherestha, 2015) include the absence of bracing or the falling of walls out of plane as the most common causes of collapse in traditional architecture and in Adil, (2017) a more exhaustive study of the failures of masonry structures in earthquakes can be seen. Finally, there is no element in the buildings of the area that separates the structure above ground from the foundation to attenuate the seismic vibrations when it is recognized as one of the most basic anti-seismic methods as indicated in Tamang (2016).

In other geographical areas such as South America there is a system based on layers of clay with thixotropic properties that plasticize when subjected to vibrations, allowing the isolation of the structure. In our area of study, there is no evidence of clays and even less with these properties.

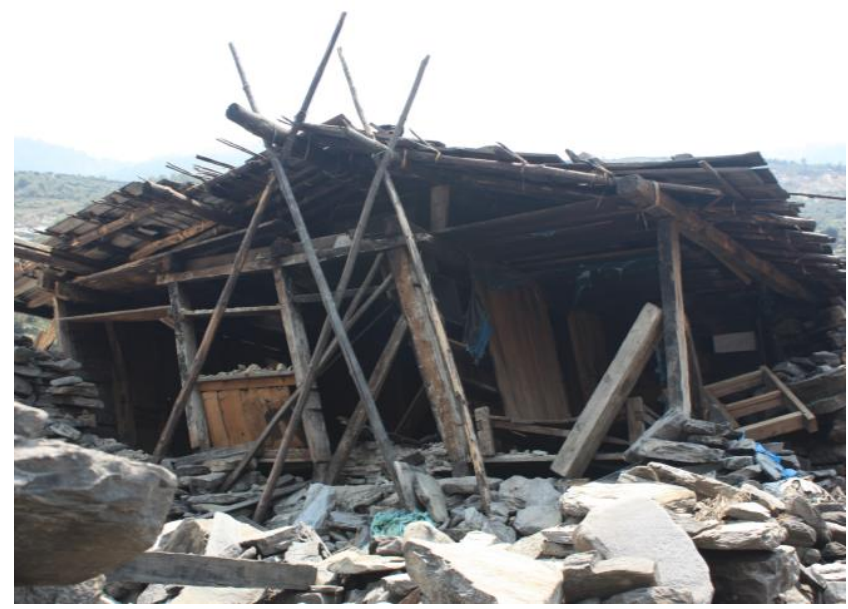

Figure 17. Collapsed house 2016 (Authors).
3.1.2 Analysis of structural behavior and proposals: As a conclusion, from a structural point of view, the wooden frame is practically detached from the stonewalls not transmitting both vertical and horizontal loads. The gap between them allows independent behavior for apparently minor earthquakes, with a magnitude of 7-8, but not for major ones (like the earthquake of 2015). Since technology is scarce, the joints are delicate and by means of woodwork, there are no bracings, no separation from the ground and durability is low. Improvements in seismic behavior would involve the use of bracing to stiffen some sections of the timber structure and, since stone walls are not stable independently, linking both of them. Thus, some confined sections are left. These sections could even be improved by using stones taken with mortar or adding horizontal elements embedded in the wall. However, the interlocking of the stone with the wood can further alter the image of traditional architecture, thus being the main issue to consider in each restoration case (Figure 18)

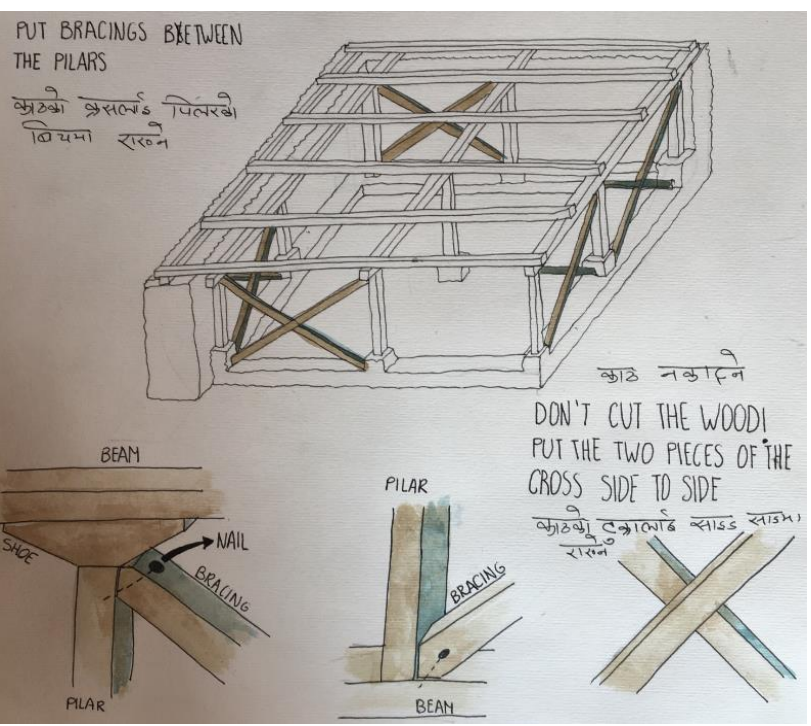

Figure 18. Bracings proposal (UEM Students).

\subsection{Habitability}

Thanks to the work done in collaboration with doctors many respiratory diseases have been diagnosed among the population, most of them due to the poor air quality in the dwellings. The stove is another invariant inside all houses; these stoves have a simple construction system with a low combustion capacity. They do not have a chimney to take out the smoke generated by the combustion of wood when cooking or heating, so this smoke has to find a path to exit the house (Figure 19).

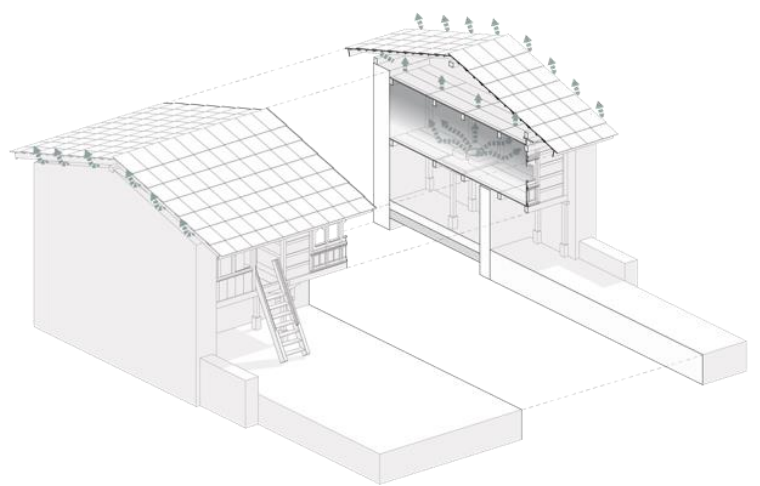

Figure 19. Air flow diagram (Authors). 
The smoke accumulates inside the house for a length of time thus considerably worsening indoor air quality.

The stove construction is very similar to a bonfire in terms of heat generation efficiency (Figure 20), a slow combustion that does not take advantage of the calorific value of the wood, a limited range of action that works mainly through direct radiation of the flame and the coal, losing a lot of heat in the process. Besides, this slow combustion generates more toxic particles than usual.

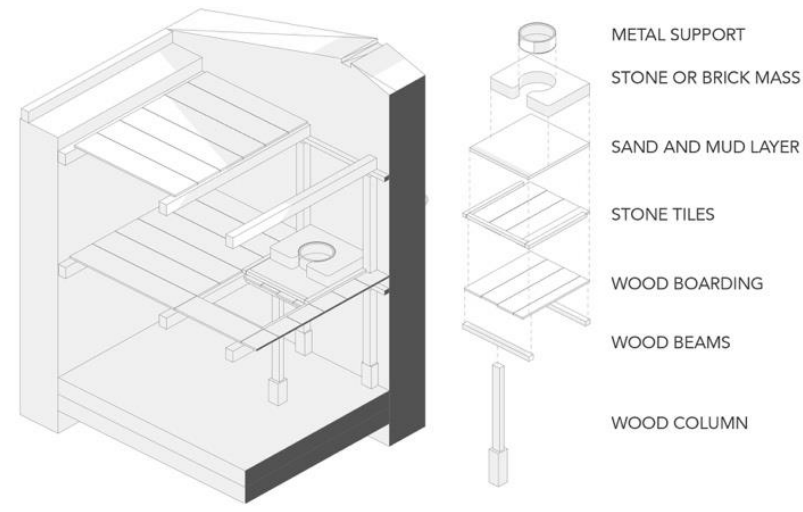

Figure 20. Axonometric stove section (Authors).

The wood used in Gatlang stoves is Himalayan cedrus, a soft wood that is so good and resistant for handicrafts but not for use as fuel. Besides, Gatlang people does not make a proper predrying process.

This affects people health in many ways, the inhalation of the particles generated directly by the combustion of the fuels used, the lack of ventilation and the accumulation of moisture enhance the appearance of moisture and mold, this is enhanced by the cold temperatures in certain months of the year, with lung disease being the most prevalent.

Changes as the introduction of chimneys or the improvement of the stoves combustion would significantly make a progress in the quality of life of Gatlang people. Rocket stoves are good examples of simple-to-run combustion systems with a highenergy efficiency that would help reducing the concentration of indoor toxic particles produced by combustion. Besides, the introduction of chimneys for the extraction of gases should be studied under the perspective of a general impact in the image of the traditional dwellings.

\section{ACKNOWLEDGEMENTS}

It is necessary to thank the NGO Orche and the UEM for the possibility they have given us to make the corresponding data survey. In addition, thanks to the collaboration of local people like Durga, Nyma or Dawa Tamang. Also, to the Escuela Politécnica de Cuenca of the UCLM for funding the assistance to the Heritage 2020.

\section{REFERENCES}

Adil M., Rashid A., Narayanan S., 2017. Constructional deficiencies in masonry structures and seismic risk. Research Gate publication/321137011.
Agullo de Rueda, J., Castilla Pascual, F., 2019. Comportamiento sísmico de la construcción tradicional Tamang en el norte de Nepal. Actas XI Congreso Nacional de Historia de la Construcción- October 2019.

Emergency Architects. 2016. "Study of habitat typologies and solutions for their seismic reinforcement nepal". Francia: www.archi-urgent.com.

Gautam D., Rodrigues H., Bhetwal K., Sanada Y., 2015. Observed damage patterns on buildings during 2015 gorkha (nepal) earthquake. Research Gate publication/283324459.

Gautam R., Pajaprati J., Valencia K., Kumar K., Neupane P., 2016. Disaster resilient vernacular housing technology in Nepal. Geoenviromental Disasters, 2016, 3:1.

Global Assessment of Risk, 2009. Nepal country report. Nepal: ISDR-UNDP.

Oliver, P., 1998a. Encyclopedia of vernacular architecture of the world. v.2. Cultures and habitats. Cambridge University Press. (1024-1044)

Oliver, P., 1998b. Encyclopedia of vernacular architecture of the world. v.1. Theories and principles. Cambridge University Press. (746)

Parajuli, H., 2009. Dynamic analyses of low strength masonry houses based on site specific earthquake ground motions. Japón: Kyoto University.

Parajuli, R., Kiyono, J., 2015. Ground motion characteristics of the 2015 Gorkha earthquake, survey of damage to stone masonry structure and structural field tests. Frontiers in build environment 10.3389/fbuil.2015.00023.

Sherestha B. 2015. Reconnaissance investigation on the damages of the 2015 Gorkha earthquake, Nepal. Australia: Center for Infrastructural Protection and Monitoring, Curtin University.

Singh, A., Jawaid A., Ram, S., 2016. A study on earthquake resistant construction in Nepal. IJRASET, Volume 4, Issue IV, April 2016.

Tamang, P., Gupta, K., 2016. Study on earthquake resistant building-base isolation. IJETT, Volume 33, Number 9- March 2016. 